\title{
Negotiating solidarity between indigenous and transformative paradigms in evaluation
}

\section{Fiona Cram and Donna M. Mertens}

Indigenous evaluators, and evaluators who position themselves in the transformative paradigm, share a common interest in positive transformation for those who experience discrimination and oppression. The determination of strategies for exploring how evaluators can contribute to positive transformation is complex territory. In this article we explore the common ground and divergent beliefs of indigenous and transformative evaluators in terms of assumptions about the nature of ethics, reality, relationships and knowledge, and methodologies. Transformative evaluators provide a pathway to explore inclusion of indigenous communities in their full heterogeneity as a way to respect multiple cultural identities. Indigenous evaluators provide a pathway to explore aspects of culture that are related to the meaning of transformation within this specific context, spirituality and historical oppression. While not always a comfortable fit, this article reveals possibilities for evaluators to improve their responsiveness to marginalised communities' needs in their full diversity and to respect the multiple cultural positions that rest therein while working for positive transformation. 
Members of marginalised communities experience discrimination and oppression. Researchers and evaluators who seek to improve circumstances for members of these communities find they face challenges in determining how to support positive transformation for these communities and the environments in which they live. These challenges include identifying and supporting a broad range of stakeholders in culturally responsive ways. Evaluators and researchers can then ascertain the historical, contextual, political, and social factors they need to consider if their evaluations are to have the desired effect. In this article we explore two positionalities that share this goal of contributing to positive transformations: transformative and indigenous evaluation. The transformative paradigm (Cram \& Mertens, 2015; Mertens, 2015; Mertens \& Wilson, 2012) provides a metaphysical umbrella under which those interested in research and evaluation with a social justice and equity focus can shelter, network, and dialogue. Our question in this space is whether the transformative umbrella provides a space where indigenous peoples can come together with others to discuss individual and intersecting transformational agendas, and the role transformative evaluation can play in helping us achieve our aspirations for a better world.

Indigenous researchers and evaluators, and those who work within the transformative paradigm, share goals for supporting transformation in the interest of communities that experience discrimination and oppression. Given this commonality, we believe that a dialogue between the two positionalities is merited to explore positive outcomes that might strengthen researchers' and evaluators' abilities to address the goal of transformation and to identify areas of potential tension. To this end, we examine the philosophical assumptions of the transformative paradigm and put them in conversation with the scholarship of indigenous researchers and evaluators. This is needed if there is to be serious consideration of any alignment-let alone 
solidarity - between these two paradigms. Key to any such dialogue is the acknowledgement of indigenous self-determination, the extension of the respectful relationships described within the transformative paradigm to be inclusive of the environment and the cosmos, and the addition of decolonisation to the transformative agenda of social justice and equity. From this foundation, an ongoing conversation between transformative and indigenous paradigms may inform transformation that will be inclusive of all peoples.

\section{About paradigms}

Thomas Kuhn (1962/1970) popularized the term paradigm within research communities with the publication of The Structure of Scientific Revolutions. The science worldview that Kuhn was describing through his use of paradigm was one that determined the acceptability of theories and the appropriateness of research methods for the investigation of phenomenon. When Guba and Lincoln $(1989,2005)$ drew on Kuhn's work to describe shifts in thinking in the social sciences they accepted that paradigms justified research approaches and, when these approaches were no longer able to explain phenomena, a new worldview would emerge. Guba and Lincoln (1994) defined an inquiry paradigm "as the basic belief system or worldview that guides the investigator" (p. 105). They did not, however, follow Kuhn and posit the displacement of an old worldview by a new paradigm. Rather, they allowed for the co-existence of paradigms when each reflected a fundamentally different approach to research.

The transformative paradigm represents a worldview based on the premise that researchers and evaluators have an ethical responsibility to address issues of social justice and human rights. Mertens (2015) developed this paradigm in response to the lack of inclusion of members of marginalised communities in decisions about research and evaluation that affected their lives, and an outcry from members 
of those communities that they were not seeing positive changes as a result of research done "on" them. Mertens built on the work of Guba and Lincoln (1989; 2005) in which they identified four types of philosophical assumptions that could be used to characterise major approaches in the social research community. A brief definition of the philosophical concepts that constitute a paradigm in this social science context is provided by Mertens (2009, p. 43):

- Axiology - the nature of ethics

- Ontology - the nature of reality

- Epistemology - the relationship between the knower and what would be known

- Methodology - appropriate approaches to systematic inquiry

Like Guba and Lincoln (1994), who added their "commitment to constructivism" (p. 105) as a proviso to their discussion of paradigms, we also state clearly that we are committed to social justice, equity, and decolonisation. Our description of paradigms should therefore be read in this light. We also note Guba and Lincoln's (1994) reminder that, however well we might argue for a paradigm or for the interface of paradigms, we are mounting a philosophical debate based on axiological, ontological, epistemological, and methodological assumptions. This "set of basic beliefs ... must be accepted simply on faith (however well argued) [as] there is no way to establish their ultimate truthfulness" (Guba \& Lincoln, 1994, p. 197). With these provisos in mind we begin our dialogue between transformative and indigenous paradigms.

\section{Transformative paradigm / indigenous paradigms}

Evaluators have choices of paradigms and methodologies that reflect different philosophical assumptions that can be used as a basis for addressing social justice and equity issues (Alkin, 2013; Mertens \& 
Wilson, 2012). However, members of marginalised communities expressed dissatisfaction with research conducted in their communities because their voices were not represented in the evaluation community and findings of evaluation studies were not being used to bring about the desired transformation that they needed. The transformative paradigm emerged in response to this expression of dissatisfaction as a way to legitimate inclusion of diverse voices and to establish a home for exploration of methodologies that have an explicit goal of furthering human rights and social justice. The transformative paradigm "pulls together many strands of philosophy that focus on issues of power and on addressing inequities in the name of furthering human rights and social justice" (Mertens \& Wilson, 2012, p. 162). Four primary principles constitute the transformative paradigm's axiological assumptions: cultural respect, social justice, human rights, and the reduction of inequities. The ontological assumption of the transformative paradigm is that our world is multifaceted, with different opinions about what is real emanating from different societal and cultural positions. The epistemological assumption is that knowledge is "constructed within a context of power and privilege with consequences attached to which version of knowledge is given privilege" (Mertens \& Wilson, 2012, p. 170). And finally, the methodological assumptions are that no single methodology is privileged; rather, methodological decisions are tied to social-justice aspirations. Methodology includes a structural analysis and facilitates a "critical and reflexive relationship between evaluator and the stakeholders" (Mertens \& Wilson, 2012, p. 172). These assumptions are explored further below.

Some indigenous researchers and evaluators describe their overall approach as a paradigm (Chilisa, 2012; Cram \& Phillips, 2012; Hart, 2010; Henry \& Pene, 2001; Wilson, 2008). When thinking about an indigenous framing for systematic inquiry in terms of a 
paradigm, the definition of a worldview by Robert-Falcon Ouellette (2011) is useful.

An Aboriginal worldview describes a holistic cumulative unique world experience(s) which contains a fluid integral sense of existence and provides a framework for generating, sustaining, and applying knowledge about the physical and metaphysical universe. It may be specific to an individual, family, group, people, tribe, or nation and may be passed down over several millennia. (p. 14)

Some indigenous evaluators eschew the term paradigm in favour of evaluation methodologies (Smith, 2012; Weber-Pillwax, 1999), while others describe their evaluation work as having an indigenous theoretical lens, framework, approach, or perspective (LaFrance \& Nicols, 2010). The way indigenous evaluation is described probably reflects the many distinct indigenous populations. Regardless of the terminology used, a common theme is that indigenous evaluation is done by, with and for indigenous people and informs decolonisation (Kawakami, Aton, Cram, Lai, \& Porima, 2007; Weber-Pillwax, 1999). Māori evaluator Cavino (2013), for example, writes that evaluation from an indigenous perspective is "a performance of power within which lies the potential for the realization of indigenous sovereignty" (p. 340).

Mertens (2009; Mertens \& Wilson, 2012) has included indigenous research and evaluation within the transformative paradigm. As a result, the transformative paradigm has been learning from and adapting to take into account the worldview and learning indigenous people have about evaluation. As Mertens explains, the transformative paradigm is inclusive of those concerned with social justice for people marginalised within our communities and societies.

The transformative paradigm .... is applicable to people who experience discrimination and oppression on whatever basis, including (but not limited to) indigeneity, race/ethnicity, disability, immigrant 
status, political conflicts, sexual orientation, disability, deafness, poverty, gender, age, or the multitude of other characteristics that are associated with less access to social justice (Mertens, 2009, p. 4).

The assumptions underpinning this inclusion of indigenous research and evaluation within the transformative paradigm warrant further discussion because of experiences indigenous peoples have had of being courted, threatened, and cajoled by the social justice agendas of other marginalised groups. A key difficulty in these previous alliances has been the lack of recognition that indigenous peoples are indigenous first and foremost (Barker, 2011). Any engagement between the transformative paradigm and an indigenous paradigm therefore needs to include a true connection with indigenous aspirations and the opening of a dialogue about the nature of the solidarity sought. Tuck and Yang (2012) describe how "Solidarity is an uneasy, reserved, and unsettled matter that neither reconciles present grievances nor forecloses future conflict" (p. 3). This is the sort of solidarity we aspire to between the two paradigms. At present, however, we are simply pleased to have opened up communication channels between two evaluation paradigms that seek to inform positive and inclusive systemic changes in our communities, our societies, and our world.

We do not come "fresh" to this discussion, as Mertens (2015; 2009) has been thinking and writing about indigenous evaluation within the context of the transformative paradigm for some years now. Rather, we come to explore the similarities between us, the additions made to the transformative paradigm as a result of this thinking, and some extensions to the transformative paradigm that still might be made for it to be truly inclusive of indigenous evaluation-extending the coverage of the transformative paradigm's metaphorical umbrella yet further. Why the interest in transformative paradigms by indigenous evaluators? Cavino (2013) writes that a core consideration of indigenous evaluation (in this case, kaupapa 
Māori evaluation) is the "prerogative to make a positive difference" (p. 348). Part of exercising this prerogative is the search for parties to work alongside and support indigenous peoples and their aspirations, and we see this potential within the transformative paradigm and its commitment to structural change. We are also convinced that the consideration of solidarity between paradigms will inform good, responsive, and transformative evaluation practice for other, non-indigenous communities and peoples. To this end we use transformative philosophical assumptions as a frame for comparing indigenous and transformative positionalities. We do this to explore positive contributions that might emerge from this relationship, along with tensions that continue to exist.

\section{Axiology (Ethics)}

Axiology concerns the ethics we bring to our evaluation practice. Axiological assumptions are made explicit and prioritised within the transformative paradigm. This means that the range of possible assumptions underpinning ontology, epistemology, and methodology is constrained by the paradigm's axiological assumptions. Within these axiological assumptions, and fundamental to the transformative paradigm, is knowledge of a community's history, values and beliefs, cultural make-up, and range of norms and practices. Mertens (2009) writes,

Ethical choices in research and evaluation need to include a realization that discrimination and oppression are pervasive, and that researchers and evaluators have a moral responsibility to understand the communities in which they work in order to challenge societal processes that allow the status quo to continue. (p. 48)

Indigenous evaluation is commensurate with this axiological position in that it also attends to the landscape of a community, including the historical events that have impacted on this landscape and the people 
in it (Kawakami et al., 2007; Swisher \& Tippeconnic, 1999). The transformative axiological assumption emphasises the need for evaluators to have a responsibility to increase their understanding of the communities in which they practice. Evaluators may do this through strengthening collaborative relationships between evaluators and stakeholders, including both those in traditional positions of power, and those who are traditionally marginalised. Indigenous axiological assumptions align with the transformative principle that the essential characteristics associated with these relationships are that they are respectful and trusting (Grover, 2010). The indigenous paradigm also extends the idea of relationships through indigenous communities' requirements that indigenous evaluators come face-to-face with them, demonstrate caution, listen and look first before speaking, share their skills and knowledge, and be humble and uphold the status of the community (Cram, 2009; Smith, 2012). This includes explaining the nature of the evaluation and the form that relationships between the evaluator and community will take (LaFrance \& Crazy Bull, 2009). Such relationships need to acknowledge indigenous communities as full partners in the evaluation (Royal Commission on Aboriginal Peoples, 1996), and have been described as evaluators and community having "shared responsibility" (Morton, et al., 2013, p. 2163) (also see below, Epistemology: that shared responsibility means tipping the balance in favour of indigenous control).

Mertens and Wilson (2012, p. 166) note the positive contribution that African peoples bring to western, individualised understandings of ethics and the notion of what constitutes a relationship. Chilisa (2012, p. 408), a tribal woman from Botswana, explains this through the concept of ubuntu, meaning "humanness" or "humanity", which "underscores an I/we relationship where there is a connectedness with living and non-living things; there is a brotherhood, sisterhood, guesthood, and community togetherness" (p. 408). Many other 
indigenous peoples also have collective processes of reflection and decision-making that exhibit this type of connectedness with one another; with the earth, the oceans and rivers, animate and inanimate life as all have a life force; and with a spiritual world (Brant Castellano, 2004; Kennedy, et al., 2015; LaFrance \& Nicols, 2010). Within the context of these relationships Wilson (2008), from the Opaskwayak Cree Nation, asks an axiological question: "What is it ethical to do in order to gain this knowledge, and what will this knowledge be used for?” (p. 34). For Māori, the answer to the last part of the second question is that knowledge is to be used to uphold the mana (status) and interests of the community, not for the researchers' own gain (Makareti, 1938). Cheryl Crazy Bull (1997), a Sicangu Lakota woman, also explains:

We, as tribal people, want research and scholarship that preserves, maintains, and restores our traditions and cultural practices. We want to restore our homelands; revitalize our traditional religious practices; regain our health; and cultivate our economic, social, and governing systems. Our research can help us maintain our sovereignty and preserve our nationhood. (p. 23)

Brant Castellano (2004, p. 104), a Mohawk woman, writes that "knowledge creation for social benefit" (p. 104) can only be achieved when stakeholders agree on what constitutes "social benefit". Similarly there needs to be dialogue and agreement between the transformative paradigm and indigenous paradigm about what constitutes "equity". The transformative paradigm emphasizes a commitment to social justice and equity, whereas the transformation desired by indigenous peoples includes decolonisation, sovereignty, and the return of stolen resources (Cram \& Mertens, 2015; Tuck \& Yang, 2012). The compatibility of these agendas has been tested; for example, during the 
Occupy movement ${ }^{1}$ occupiers in the United States failed to recognise that they were occupying traditional indigenous lands that were already the sites of colonial occupation.

I had hoped that you would address the centuries-long history that we indigenous peoples of this continent have endured being subject to the countless '-isms' of do-gooders claiming to be building a 'more just society,' a 'better world,' a 'land of freedom' on top of our indigenous societies, on our indigenous lands, while destroying and/ or ignoring our ways of life (Montano, 2011).

When indigenous peoples speak about decolonisation and returning to their lives as indigenous, they are describing a discipline of daily life that is informed and affirmed by traditional knowledge, values and beliefs (Te Awekotuku, 1991; Brant Castellano, 2004). As culture is not static, this discipline of daily living is inevitably bound to be some combination of the knowledge, beliefs, and values that have been maintained, revitalised, and innovated during times of colonisation (Smith, 2012). Adopting the words of W.E.B. Du Bois (1920), decolonisation is about the decentring of whiteness as the owners of the world forever (Ormond, Cram, \& Carter, 2006). For this to be a joint project between transformative and indigenous paradigms, the sovereign status of indigenous peoples needs to be acknowledged (LaFrance, 2004; Weber-Pillwax, 1999). This may sound simple, but surprisingly, even talk about cultural responsiveness can overlook and ignore the history of colonisation experienced by many indigenous peoples and the consequent need to challenge racism and recognise indigenous sovereignty (Castagno \& Brayboy, 2008). Decolonisation and self-determination are therefore primary axiological assumptions of the indigenous paradigm.

1 The Occupy movement, 2011-12, was a protest against worldwide social and economic inequalities. It began in Manhattan's financial district and grew to see camps of people established in public sites in cities and towns around the world. 
In summary, the privileging of axiological assumptions within the transformative paradigm is compatible with an indigenous evaluation paradigm. The extensions to the transformative paradigm that are needed to accommodate indigenous peoples are the acknowledgement of indigenous sovereignty, a broadening of understanding about who our relations are (to encompass the genealogical connectedness indigenous people have with their world), and an embracing of a collective notion of ethics, wellbeing, and respect for all living and non-living things; as well as the embracing of decolonisation within the meaning of transformation. This discussion of assumptions about axiology leads to a consideration of the ontological assumption that is used to guide thinking in the transformative and indigenous sense.

\section{Ontology (Reality)}

The transformative ontological assumption is that reality is multifaceted because people's life experiences and values are diverse. This diversity is however not neutral; rather those with power within society are able to privilege their own reality. The ontological task of the transformative paradigm is therefore the interrogation of whose reality is privileged and the inequities that flow from acceptance of the dominant version of reality for those who have a marginalised version of reality (Mertens \& Wilson, 2012).

Indigenous people are often very well aware of the existence of multiple realities as they live in at least two worlds, with their own world being marginalised by colonisers who have privileged their own reality (Reid \& Cram, 2004; Smith, 2012). Cindy Blackstock (2009) from the Gitksan Nation, for example, stresses the existence of these two worlds in her ontology of First Nations people in Canada, including:

- First Nations believe their ancestors were right about most things, and westerners believe their ancestors were either wrong or their ideas could be substantially improved upon. 
- First Nations ontology and science are constructed as part of the natural world, whereas western culture largely views human experience as separate from the natural world.

- First Nations believe there are sufficient resources to meet everyone's needs, whereas westerners focus on a scarcity of resources primarily driven by a conflation of want and need. (p. 3)

Key to the ontological assumptions of kaupapa Māori (by Maori, for Maori) evaluation are kinship relationships_-whanaungatanga — that include genealogical or whakapapa connections with the natural environment and the spirit world. These relationships are made explicit within pepeha, or tribal sayings. "Used orally, the combination of ... three cornerstones - whanaungatanga, whakapapa, and pepehalocates Maori in a three-dimensional landscape; they are a cultural positioning system" (Cram, Kennedy, Paipa, Pipi, \& Wehipeihana, 2015, p. 297). Brant Castellano also explores the importance of such a positioning system when she writes about the relationships between indigenous people's worldviews, values, ethics, and protocols through the metaphor of a tree. In this metaphor, "the perception of reality underpinning life as it is lived, like the roots of the tree, is not ordinarily visible" (Brant Castellano, 2004, p. 100). Reality is embedded and maintained through language, ceremony, and relationships.

Indigenous ontology is also inclusive of dreaming. Writing about Ojibway ontology, Hallowell (1975) notes that "although there is no lack of discrimination between the experiences of self when awake and when dreaming, both sets of experiences are equally self-related" (p. 165). Hawai' ian scholar Kahakalau (2004) also writes about the reality of dream experiences when she describes dreaming the analysis of her PhD findings. Cree scholar Hart (2010) places such experiences into the spiritual realm and describes the two key factors of indigenous ontology as spirituality and reciprocal relations. 
Transformative and indigenous assumptions about reality are commensurate with the notion that what is real is not necessarily visible. The transformative principle holds that the evaluator has a responsibility to make visible the realities that are operating in a context, what the sources of those realities are in terms of societal positioning, power and privilege, and challenge versions of reality that sustain an oppressive status quo (Mertens \& Wilson, 2012). The indigenous assumptions about reality extend these ideas by including a concept of reality that is more expansive in form and time, including spiritual dimensions that can aid in understanding relationships that are critical to effective evaluations. The next step in this exploration of ethical practice and determining notions of reality is to explore the epistemological assumptions about the nature of knowledge as it is understood in these two positionalities.

\section{Epistemology (Knowledge)}

The transformative paradigm turns the adage that "knowledge is power" on its head with the epistemological assumption that those in positions of power within a society are able to assert the validity and legitimacy of their own knowledge and displace and marginalise the knowledges of those who are powerless (Mertens \& Wilson, 2012). Epistemologically, transformative evaluators are aware of the need to understand relationships that are imbued with more or less power and to bring together voices from all constituencies to address issues of social justice and human rights.

Brant Castellano (1997) defined three kinds of Aboriginal knowledge that extend thinking on the nature of knowledge: Traditional Knowledge: handed down through the generations; Empirical Knowledge: gained through careful observation; and Revealed Knowledge: acquired through dreams, visions, and spiritual protocol. Transformative evaluators need to be aware that the traditional 
knowledge held by indigenous peoples is rightfully theirs; they alone can decide how much to share and with whom. Empirical knowledge is that which is usually considered in the conduct of evaluations and should be co-constructed with indigenous peoples. Revealed knowledge is a unique indigenous contribution to transformative thinking about epistemology and thus presents fertile ground for conversations between transformative and indigenous evaluators.

Indigenous epistemologies can be further understood through a Māori view of the world as one of connectedness and relationships between Māori, the natural environment, and the universe. Whakapapa means 'to lay one thing upon another', as in one generation upon the next. Māori scholar Barlow (1991) writes "Whakapapa is a basis for the organisation of knowledge in respect of the creation and the development of all things" (p. 173). Màtauranga Māori, often translated as "knowledge", is a tool for organising and thinking about knowledge, including about our place in the world (Mead, 2003). There is also sacredness about mātauranga Māori and therefore cultural practices tied to knowledge and learning. These cultural practices invariably acknowledge and work within a web of relationships.

Manulani Aluli Meyer (2001) describes several categories that help her think about Native Hawaiian epistemology. The first is spirituality, meaning the relationship people have with their world. The second is culture and how this shapes and mediates peoples' relationship with their world. Third, relationships with people, relativesalive and deceased — and with the environment mediate how people see, experience, and understand. Fourth is utility, the usefulness of knowledge that makes it meaningful. The fifth category, words, is about language and causality. Meyer describes the Hawaiians speaking in imagery and metaphor as "words cause something". The last category is about the site of emotion and intellect residing in the na'au or gut where knowledge is "percolated"; there is no mind-body 
separation. Wilson (2008) continues the indigenous thread into the epistemological domain by emphasising the relational nature of knowledge, in this way:

Knowledge is shared with all creation. It is not just interpersonal relationships, just with the research subjects I may be working with, but it is a relationship with all of creation. It is with the cosmos; it is with the animals, with plants, with the earth that we share this knowledge. It goes beyond the individual's knowledge to the concept of relational knowledge...you are answerable to all your relations... (p. 56)

Indigenous evaluators seek out the creators of knowledge or philosophers within their communities, as they are the keepers of indigenous epistemology (Weber-Pillwax, 1999). Relationships of trust are key as knowledge is sharing within the context of relationships and with the approval of those whose role it is to protect such knowledge. This is also important because the indigenous programmes and services that are evaluated are often built upon, or tailored to respond to, the same indigenous epistemology that indigenous evaluators are aiming to honour and represent within their evaluation reporting (Grover, 2010; Pipi et al., 2003).

The same collaborative model expounded here for evaluation is more and more frequently being used by public-health practitioners to infiltrate public-health messages and practices into indigenous communities alongside, and in compatibility, with a community's own cultural norms and wisdom (Symlie, Kaplan-Myrth, \& McShane, 2008). This is also a growing practice among others wanting new knowledge to be taken up and spread throughout indigenous communities. A key learning across these disciplines is that the centre of control and decision-making within collaboratives needs to reside firmly with indigenous communities so that any decisions or processes do not undermine the self-determination of 
a community. Collaboration is not about "democratic or equal participation in decision-making" (Cargo, Delormier, Lévesque, HornMiller, McComber, \& Macaulay, 2008, p. 904); rather, it is about indigenous peoples having the final say.

Transformative and indigenous epistemologies share characteristics in understanding that knowledge is created through trusting relationships that are respectful of cultural norms. Both also reflect an understanding that knowledge is mediated through power relationships and that the control of the research needs to be in the hands of members with the lived experiences, whether that is members of the Deaf community (Harris, Holmes, \& Mertens, 2009) or the indigenous community. The explicitness of the cultural norms, content, and practices included in indigenous scholarship extends thinking about the nature of knowledge in a transformative sense. In addition, indigenous scholars add important dimensions to the nature of knowledge that are rooted in spiritual ways of knowing, expansive notions of knowing, and respect for the rightful ownership of knowledge. As evaluators reach greater clarity about their assumptions related to the nature of ethics, reality, knowledge and relationships, they can derive their methodological assumptions that align with their previous assumptions.

\section{Methodology (Systematic inquiry)}

The three previous assumptions set the scene for the transformative paradigm's methodological assumptions. Methodological decisions are made on the basis of their potential to facilitate transformation, their ability to enable a structural analysis, and their inclusion of critical, reflexive relationships between evaluators and stakeholders (Mertens \& Wilson, 2012). A transformative cyclical model of methodology illustrates how evaluators can work respectfully with communities to facilitate the use of evaluation processes and findings 
to further social justice and human rights. Evaluation planning includes members of marginalised communities, as well as those in power, in order to strengthen relationships and to mould an approach that is responsive to their needs. As data are collected, they are shared with stakeholders for collaborative interpretation and decisions about how evaluation findings can be used to further progress toward the desired transformation.

Indigenous methodology is also about systematic inquiry. Indigenous ways of knowing are sourced within their own values and beliefs, and their knowledge is positioned within a reflexive cycle (Henry \& Pene, 2001). As Brant Castellano (2004) wrote, "Aboriginal knowledge has always been informed by research, the purposeful gathering of information and the thoughtful distillation of meaning" (p. 98) The ethics workbook for the Manitoulin Area First Nations (Maar, McGregor, \& Manitowabi, 2011) simply notes "methodologies must be culturally acceptable at the community level" (p. 2). Ermine, Sinclair and Browne (2005) expanded on this by describing the importance of methodology adhering to local norms and protocols, which often "adds layers of complexity that may or may not be immediately apparent" (p. 39). Like transformative evaluators, indigenous methodologists suggest beginning studies with establishing the nature of social relationships in the community, while reflexively considering their own positionality as evaluators in the transformation process (Chilisa, 2012; Mertens \& Wilson, 2012; Wilson, 2008). This immersion in a community may also bring about changes in how indigenous evaluators think of themselves and their roles and responsibilities (Weber-Pillwax, 1999).

Transformative evaluators and indigenous evaluators also agree that privileging the voice of the oppressed does not mean focusing solely on the deficits and disparities impacting on marginalised communities. The transformative paradigm emphasises focusing on 
the strengths and resilience in the communities, as well as the challenges that are experienced due to an oppressive status quo (Mertens \& Wilson, 2012). Indigenous peoples, as well as members of other oppressed groups, may or may not be poor and marginalised, as there is a growing indigenous middle class in many places. Regardless of socioeconomic status, indigenous people have needs alongside ambitions, aspirations and dreams for themselves and future generations. Kawakami and colleagues (2007) advocate that indigenous evaluation must "promote and practice an indigenous worldview" (p. 319). Authentic representation of indigenous peoples within evaluation reporting is about being true to "the reality of the lived indigenous experience" (Weber-Pillwax, 1999, p. 42). This is more than a focus on overcoming disadvantage or eliminating disparities. It is about the needs and priorities that indigenous people identify themselves, and about their own aspirations and dreams (Malezer, 2013). The meandering (rather than linear) pathways of connections and relationships are embedded within indigenous languages, with knowledge coming from keen observation and interpretative messages (Deloria, Jr, 1999). In this way evaluators are well placed to capture the likely meandering journey of an indigenous programme, and to the create "knowledge through careful observation and constant reflection" (LaFrance \& Nichols, 2009, p. 27).

The evaluator's role is also to recognise the wider context in which a programme is operating. Similar to transformative evaluators, indigenous peoples "are engaged in a struggle to re-establish ethical order in their communities and nations" (Brant Castellano, 2004, p. 112). This includes, for example, the struggle to regain control over governance, over the education of young people, over the justice that is meted out to offenders, and over access to health and wellness for all people. In this struggle there is a need to acknowledge the structural determinants (both enablers and barriers) of indigenous people 
being able to live indigenous lives. This means that indigenous and transformative evaluations begin two steps back from where many other evaluations begin, recognising that the social, political, and historical foundations of any initiative need to be understood, along with any adaptations a community has made in order to make a solution something more of their own (Cram, 2015).

Methodologically, transformative and indigenous evaluators share important axioms that emanate from their axiological assumptions. Inclusion of community members in respectful and meaningful ways is a key component of both, along with a recognition of strengths and challenges in the communities, the importance of which languages are given priority, and the need to structure evaluations in ways that insure reciprocity in the form of making progress toward the desired transformation. Indigenous evaluators provide additional thought on how the evaluation process can be adapted to the cultural way of being, perhaps requiring a more meandering, non-linear approach.

\section{Conclusion}

Alfred (2005) writes that indigenous peoples:

having had their freedom stolen and their civilizations crushed by colonialism ... are well aware of the social and political crisis they face. But the crucial goal of restoring a general respect for traditional values, and reconnecting our social and political life with traditional teachings remains elusive (p. 23).

He attributes this to indigenous leaders being compromised. While indigenous scholars, researchers and evaluators may be in the lower echelons of indigenous leadership, they must still channel a compulsion for self-determination and the redistribution of stolen resources. This does not mean a rejection of non-indigenous theory or knowledge. "Rather, it is about centering our concerns and worldviews and then coming to know and understand theory and research from 
our own perspectives for our own purposes" (Smith, 1999, p. 39). With these incentives in mind it is timely that the transformative and indigenous paradigms can be used to inform old understandings about evaluation and spark new ones.

In this article, the philosophical assumptions that constitute a framework for research that serves members of marginalised communities - indigenous and otherwise- - have served to further a conversation between transformative evaluation and indigenous evaluation. This ongoing conversation is needed so that indigenous philosophies and aspirations inform the transformation of the world into a more just and equitable place. We do not want to experience "jagged worldviews colliding", as Leroy Little Bear (2000, p. 77) described the meeting between indigenous worldviews and positivist scientific thought, or the invalidation of indigenous worldviews when they are appropriated by non-indigenous paradigms (Cavino, 2013). Instead we have sought a space where an authentic exchange can take place to increase understanding.

Ermine (2007) describes the spaces where these types of conversation take place as "ethical spaces" (p. 193), while Cram and Phillips (2012) describe them as interstitial spaces; namely, "spaces that connect recognised spaces but are often overlooked and therefore under-designed...[where] the under-designed space provides an opportunity for rituals of encounter and the potential for relationship building" (p. 39). In both cases it is a neutral meeting space between world views that comes about when each paradigm names itself and is then willing to dialogue by bringing, rather than imposing, its worldview on the discussion space. This allows us to get beyond politeness and its accompanying façade of dialogue (Weber-Pillwax, 1999).

At this point we revisit the question we raised at the beginning of this article: whether the transformative umbrella provides a space where indigenous peoples can come together with others to discuss 
both individual and intersecting transformational agendas, and the role transformative evaluation can play in helping us achieve our aspirations for a better world. The commonalities identified in this article provide a tentative affirmative response to this question. The unique contributions of transformative and indigenous evaluators provides opportunities for growth in thinking and practice that has the potential to increase the positive transformations that are sorely needed. The transformative umbrella provides an opportunity to explore the meaning of multiple dimensions of diversity that are used as a basis for discrimination and oppression. Many people understand the plight of having their resources redistributed to newcomers, or of missing out on the resources of society because they are a member of an oppressed group (Chilisa, 2012). This is not just the plight of indigenous peoples. The consequences of this oppression and marginalisation are seen in people's poorer health, poorer education, and fewer opportunities to be seen as fully human (Smith, 2012). Many of the people in marginalised places and spaces may also belong to two or more oppressed cultures, with their experiences amplified as a result (Richards, 2005).

A connection between transformative and indigenous paradigms may create "safe" spaces where agendas can be discussed and debated, and where all peoples might begin to see the value of decolonisation within their own social-justice agendas. We all need to move beyond a colonial mindset in order to achieve equity. If this were to occur, then perhaps those with potentially conflicting and therefore isolating identities would find themselves being able to speak about their conflicts and their own aspirations for resolution and some sense of unity. As a majority of the world's population resides in places and spaces where a transformed world is needed to catalyse inclusion and the equitable redistribution of resources, such a space under the transformative umbrella will surely be productive for indigenous agendas including evaluation. 
Yet, we must end on a note of caution. Indigenous evaluators present ideas that are not easily accepted by the political powers in terms of issues related to land and identity. Their contribution to divergent understandings of ethics, reality, and knowledge in terms of spirituality and dreams are not commensurate with thinking that holds that evaluation should be based on empirical data, defined as that which can be observed and measured. As the transformative paradigm puts priority on cultural understandings and respect, these issues are food for challenging thinking.

He waka eke noa

A canoe that we are all in, with no exception

\section{Acknowledgement}

Our thanks to the reviewers for their helpful comments, and to Heather Hamerton from the journal editorial board for acting in an editorial role for this article.

\section{References}

Alfred, T. (2005). Sovereignty. In Sovereignty matters: Locations of contestation and possibility in indigenous struggles for self-determination (pp. 33-50). Lincoln, NE: University of Nebraska Press.

Alkin, M. C. (Ed.) (2013). Evaluation roots (2nd ed.). Thousand Oaks, CA: Sage.

Barker, J. (2011). Native acts: Law, recognition, and cultural authenticity.

Durham \& London, UK: Duke University Press.

http://dx.doi.org/10.1215/9780822393382

Barlow, C. (1991). Tikanga whakaaro: Key concepts in Mãori culture.

Auckland: Oxford University Press.

Blackstock, C. (2009). Why addressing the over-representation of First

Nations children in care requires new theoretical approaches based on

First Nations ontology. Journal of Social Work Values \& Ethics, 6(3), 1. 
Brant Castellano, M. (2004). Ethics of aboriginal research. Journal of Aboriginal Health, January, 98-114.

Brant Castellano, M. (1997, May). Partnership: The key to ethical cross-cultural research. Speech presented to the Canadian Evaluation Society, Ottawa, ON.

Cargo, M., Delormier, T., Lévesque, L., Horn-Miller, K., McComber, A., \& Macaulay, A. C. (2008). Can the democratic ideal of participatory research be achieved? An inside look at an academic indigenous community partnership. Health Education Research, 23(5), 904-914. http://dx.doi.org/10.1093/her/cym077

Castagno, A. E., \& Brayboy, B. M. (2008). Culturally responsive schooling for indigenous youth: A review of the literature. Review of Educational Research, 78(4), 941-993. http://dx.doi.org/10.3102/0034654308323036

Cavino, H. M. (2013). Across the colonial divide: Conversations about evaluation in indigenous context. American Journal of Evaluation, 34(3), 339-355. http://dx.doi.org/10.1177/1098214013489338

Chilisa, B. (2012). Indigenous research methodologies. Thousand Oaks, CA: Sage.

Cram, F. (2009). Maintaining indigenous voices. In D. Mertens, \& P. Ginsberg (Eds.), SAGE Handbook of social science research ethics (pp. 308-322). Thousand Oaks, CA: Sage. http://dx.doi.org/10.4135/9781483348971.n20

Cram, F. (2015). Harnessing global social justice and social change with multiple and mixed method research. In S. N. Hesse-Biber, \& R. B. Johnson (Eds.), The Oxford handbook of mixed and multiple methods research (pp. 667-687). New York, NY: Oxford University Press.

Cram, F., \& Mertens, D. (2015). Transformative and indigenous frameworks for mixed and multi method research. In S. N. Hesse-Biber \& R. B. Johnson (Eds.), The Oxford handbook of mixed and multiple methods research (pp. 99-109). New York, NY: Oxford University Press.

Cram, F., \& Phillips, H. (2012). Reclaiming a culturally safe place for Māori 
researchers within multi-cultural, transdisciplinary research groups. International Journal of Critical Indigenous Studies, 5(2), 36-49.

Cram, F., Kennedy, V., Paipa, K., Pipi, K., \& Wehipeihana, N. (2015). Being culturally responsive through kaupapa Māori evaluation. In S. Hood, R. Hopson, \& H. Frierson (Eds.), Continuing the journey to reposition culture and cultural context in evaluation theory and practice (pp. 289-311). Charlotte, NC: Information Age Publishing.

Crazy Bull, C. (1997). A native conversation about research and scholarship. Tribal College Journal, 9, 17-23.

Deloria, Jr, V. (1999). Spirit and reason: The Vine Deloria, Jr, reader. Golden, CO: Fulcrum Publishing.

Du Bois, W. (1920). The souls of whitefolk. In N. Huggins (Ed.), W.E.B. Du Bois: Writings. New York: Library of America.

Ermine, W. (2007). The ethical space of engagement. Indigenous Law Journal, 6(1), 193-203.

Ermine, W., Sinclair, R., \& Browne, M. (2005). Kwayask itôtamowinIndigenous research ethics: Report of the Indigenous Peoples' Health Research Centre to the Institute of Aboriginal Peoples' Health and the Canadian Institutes of Health Research. Regina, SK: Indigenous People's Health Research Centre.

Grover, J. G. (2010). Challenges in applying indigenous evaluation practices in mainstream grant programs to indigenous communities. The Canadian Journal of Program Evaluation, 23(2), 33-50.

Guba, E. G., \& Lincoln, Y. S. (1994). Competing paradigms in qualitative research. In N. K. Denzin, \& Y. S. Lincoln (Eds.), Handbook of qualitative research (pp. 105-117). Thousand Oaks, CA: Sage.

Guba, E. G., \& Lincoln, Y. S. (1989). Fourth generation evaluation. Newbury Park, CA: Sage.

Guba, E. G., \& Lincoln, Y. S. (2005). Paradigmatic controversies, contradictions, and emerging confluences. In N. K. Denzin, \& Y. S. Lincoln (Eds.), The SAGE handbook of qualitative research (3rd ed., pp. 
191-215). Thousand Oaks, CA: Sage Publications.

Hallowell, A. I. (1975). Ojibway ontology, behavior, and world view. In D. Tedlock, \& B. Tedlock (Eds.), Teachings from the American earth: Indian religion and philosophy (pp. 141-178). New York: Liveright.

Harris, R., Holmes, H., \& Mertens, D. (2009). Research ethics in sign language communities. Sign Language Studies, 9, 104-131. http://dx.doi.org/10.1353/sls.0.0011

Hart, M. A. (2010). Indigenous worldviews, knowledge, and research: The development of an indigenous research paradigm. Journal of Indigenous Voices in Social Work, 1(1), 1-16.

Henry, E., \& Pene, H. (2001). Kaupapa Māori: Locating indigenous ontology, epistemology and methodology within the academy. Organisation, 8, 234-242. http://dx.doi.org/10.1177/1350508401082009

Kahakalau, K. (2004). Indigenous heuristic action research: Bridging Western and indigenous research methodologies. Hülili: Multidisciplinary Research on Hawaiian Well-Being, 1(1), 19-34.

Kawakami, A., Aton, K., Cram, F., Lai, M., \& Porima, L. (2007). Improving the practice of evaluation through indigenous values and methods: Decolonizing evaluation practice—returning the gaze from Hawai' $i$ and Aotearoa. In P. Brandon, \& P. Smith (Eds.), Fundamental issues in evaluation (pp. 219-242). New York: Guilford Press.

Kennedy, V., Cram, F., Paipa, K., Pipi, K., Baker, M., Porima, L., et al. (2015). Beginning a conversation about spirituality in Māori and Pasifika evaluation. In S. Hood, R. Hopson, \& H. Freirson (Eds.), Continuing the journey to reposition culture and cultural context in evaluation theory and practice (pp. 151-178). Charlotte, NC: Information Age Publishing.

Kuhn, T. S. (1962/1970). The structure of scientific revolutions (2nd ed.). Chicago: University of Chicago Press.

LaFrance, J. (2004). Culturally competent evaluation in Indian Country. New Directions for Evaluation, 102 (Summer), 39-50. http://dx.doi. org/10.1002/ev.114 
LaFrance, J., \& Crazy Bull, C. (2009). Researching ourselves back to life: Taking control of the research agenda in Indian country. In D. M. Mertens, \& P. E. Ginsberg (Eds.), Handbook of social research ethics (pp. 135-149). Thousand Oaks, CA: Sage. http://dx.doi.org/10.4135/9781483348971.n9

LaFrance, J., \& Nichols, R. (2009). Indigenous evaluation framework: Telling our story in our place and time. Alexandria, VA: American Higher Education Consortium.

Little Bear, L. (2000). Jagged worldviews colliding. In M. Battiste (Ed.), Reclaiming indigenous voice and vision (p. 77). Vancouver: UBC Press.

Maar, M., McGregor, L., \& Manitowabi, L. (2011). Ethics and research review workbook: A resource for Manitoulin Area First Nations for the review and evaluation of research proposals. Written in collaboration with the Manitoulin Anishinaabek Research Review Committee. Manitoulin, ON: Manitoulin Anishinaabek Research Review Committee.

Makareti. (1938). The old-time Maori. London: Victor Gollancz.

Malezer, L. (2013). Challenges in evaluating indigenous policy. In P. Commission (Ed.), Better indigenous policies: The role of evaluation. Roundtable Proceedings (pp. 69-80). Canberra: Productivity Commission.

Mead, H. M. (2003). Tikanga Mãori: Living by Mãori values. Wellington: Huia.

Mertens, D. M., \& Wilson, A. T. (2012). Program evaluation theory and practice. A comprehensive guide. New York: The Guilford Press.

Mertens, D. M. (2009). Transformative research and evaluation. New York, NY: Guildford Press.

Mertens, D. M. (2015). Philosophical assumptions and program evaluation. Spazio Filosofic, 13, 75-85.

Meyer, M. A. (2001). A cultural understandings of empiricism: $A$ Native Hawaiian critique. Canadian Journal of Native Education, 25(2), 188-198.

Montano, J. P. (2011, September 24). An open letter to the Occupy Wall Street activists. Retrieved January 22, 2015, from ZASHNAIN @bedlamfury: 
Outbursts of freedom, self expression, determination...: www.zashnain.com/2011/09/open-letter-to-occupy-wall-street.html

Morton, D. J., Proudfit, J., Calac, D., Portillo, M., Lofton-Fitzsimmons, G., Molina, T., et al. (2013). Creating research capacity through a tribally based institutional review board. American Journal of Public Health, 103(12), 2160-2164. http://dx.doi.org/10.2105/AJPH.2013.301473

Ormond, A., Cram, F., \& Carter, L. (2006). Researching our relations: Reflections on ethics and marginalisation. Alternative: An international journal of indigenous scholarship, 2(1), 174-191.

Ouellette, R.-F. (2011). Evaluating aboriginal curricula using a Cree-Métis perspective with a regard towards indigenous knowledge. Unpublished doctoral thesis, Université Laval.

Pipi, K., Cram, F., Hawke, R., Hawke, S., Huriwai, T. M., Keefe, V., et al. (2003). Mãori and iwi provider success: A research report of interviews with successful Iwi and Māori providers and government agencies. Wellington: Te Puni Kōkiri.

Reid, P., \& Cram, F. (2004). Connecting health, people and country in Aotearoa/New Zealand. In K. Dew, \& P. Davis (Eds.), Health and society in Aotearoa New Zealand (2nd ed., pp. 33-48). Auckland: Oxford University Press.

Richards, P. (2005). The politics of gender, human rights, and being indigenous in Chile. Gender and Society, 19(2), 199-220. http://dx.doi.org/10.1177/0891243204272706

Royal Commission on Aboriginal Peoples. (1996). Royal Commission on Aboriginal Peoples. Ottawa, ON: Royal Commission on Aboriginal Peoples.

Smith, L. T. (1999). Decolonizing methodologies: Research and indigenous peoples. New York \& Dunedin: Zed Books \& Otago University Press. Smith, L. T. (2012). Decolonizing methodologies: Research and indigenous peoples (2nd ed.). London \& New York: Zed Books.

Swisher, K. G., \& Tippeconnic, J. W. (1999). Research to support improved 
practice in Indian education. In K. G. Swisher, \& J. W. Tippeconnic (Eds.), Next steps: Research and practice to advance Indian education (pp. 295-307). Charlestone, WV: Clearinghouse on Rural Education and Small Schools, ERIC.

Symlie, J., Kaplan-Myrth, N., \& McShane, K. (2008). Indigenous knowledge translation: Baseline findings in a qualitative study of the pathways of health knowledge in three indigenous communities in Canada. Health Promotion International, 10 (3), 436-446.

Te Awekotuku, N. (1991). He tikanga whakaaro: Research ethics in the Māori community. Wellington: Manatū Māori.

Tuck, E., \& Yang, K. W. (2012). Decolonization is not a metaphor. Decolonization: Indigeneity, Education \& Society, 1(1), 1-40.

Weber-Pillwax, C. (1999). Indigenous research methodology: Exploratory discussion of an elusive subject. Journal of Educational Thought, 33(1), 31-46.

Wilson, S. (2008). Research is ceremony. Indigenous research methods. Black Point, NS, Canada: Fernwood Publishing.

\section{The authors}

Fiona Cram, PhD (corresponding author): Katoa Ltd, PO Box 105611, Auckland City, Auckland 1143, Aotearoa New Zealand. Email: fionac@katoa.net.nz

Donna M. Mertens, PhD: Independent Consultant, United States of America 